\title{
Special issue devoted to novel trends in rheology
}

\author{
Jan Vermant • H. Henning Winter
}

Published online: 3 April 2013

(C) Springer-Verlag Berlin Heidelberg 2013

We usually define rheology as the study of deformation and flow of matter. However, our discipline is evolving at a rapid pace, and it is relevant to identify the trends and future of rheology. With this in mind, we invited a number of researchers in the early stages of their career to contribute a paper to a special issue of Rheologica Acta. We asked them to write an original contribution, which underwent the regular reviewing process, but the authors were able to comment a bit more on the reasons for doing their work and could be more speculative about the possible impact. We wanted to give these researchers, who are in the process of becoming the leaders in the field of rheology, a platform to present their work and share their ideas. We hope this will give us all a vision of the vibrant discipline of rheology. The choices of those individuals invited were made by us, as editors, and are in no way meant to be exhaustive.

We were positively surprised by the enthusiastic response to our invitations, and we will have at least two special issues this year and will follow up this initiative in the next few years. The first issue already gives a clear overview of the broad range of topics that are being dealt with.

Rheologica Acta has always been the home to papers which focus on theory or experiment or both. Not surprisingly, novel experimental tools take up an important place in the special issue. Techniques are discussed which aim

\section{J. Vermant $(\square)$}

Department of Chemical Engineering,

KU Leuven, University of Leuven,

W. de croylaan 46, 3001 Leuven, Belgium

e-mail: jan.vermant@cit.kuleuven.be

\section{H. H. Winter}

Department of Chemical Engineering, University

of Massachusetts, Amherst, MA 01003, USA

e-mail: winter@ecs.umass.edu to link high shear rheology and tribology (Clasen 2013), along with novel setups for flow visualization (Chan and Mohraz 2013) as well as methods for active and passive microrheology which even enable on to get an insight into living cells (Shindel et al. 2013; Gal et al. 2013).

The materials classes and topics also range broadly, from fundamentals in suspension mechanics (Khair and Star 2012; D’Avino 2013; van Deen et al. 2013), over more complex materials such as mixtures of foams and pastes (Kogan et al. 2013), to really complex materials such as cement formulations (Pasquino et al. 2013). In the area of polymeric systems, the applications discussed range from nonlinear viscoelasticity (Ewoldt and Bharadwaj 2013) over studies of flow-enhanced nucleation in polymers (Jolley and Graham 2012) and stimuli responsive hydrogels, either in extensional flow (Stadler et al. 2013) or at interfaces (Cohin et al. 2013).

We thank the authors for their fine contributions to the journal and hope that this collection reflects the trends in rheology. We hope you will enjoy the contributions by researchers in the early stages of their career as much as we did.

\section{References}

Chan HK, Mohraz A (2013) A simple shear cell for the direct visualization of step-stress deformation in soft materials. Rheol Acta. doi:10.1007/s00397-013-0679-5

Clasen C (2013) A self-aligning parallel plate (SAPP) fixture for tribology and high shear rheometry. Rheol Acta. doi:10.1007/ s00397-013-0683-9

Cohin Y, Fisson M, Jourde K, Fuller GG, Sanson N, Talini L, Monteux C (2013) Tracking the interfacial dynamics of PNiPAM soft microgels particles adsorbed at the air-water interface and in thin liquid films. Rheol Acta. doi:10.1007/s00397-013-0697-3 
D’Avino G (2013) Non-Newtonian deterministic lateral displacement separator: theory and simulations. Rheol Acta. doi:10.1007/ s00397-013-0680-z

Ewoldt RH, Bharadwaj NA (2013) Low-dimensional intrinsic material functions for nonlinear viscoelasticity. Rheol Acta. doi:10.1007/s00397-013-0686-6

Gal N, Lechtman-Goldstein D, Weihs D (2013) Particle tracking in living cells: a review of the mean square displacement method and beyond. Rheol Acta. doi:10.1007/s00397-013-0694-6

Jolley K, Graham RS (2012) Flow-induced nucleation in polymer melts: a study of the GO model for pure and bimodal blends, under shear and extensional flow. Rheol Acta. doi:10.1007/ s00397-012-0663-5

Khair AS, Star AG (2012) The bulk electroviscous effect. Rheol Acta. doi:10.1007/s00397-012-0662-6
Kogan M, Ducloué L, Goyon J, Chateau X, Pitois O, Ovarlez G (2013) Mixtures of foam and paste: suspensions of bubbles in yield stress fluids. Rheol Acta. doi:10.1007/s00397-013-0677-7

Pasquino R, Nicodemi F, Vanzanella V, Alfani R, Grizzuti N (2013) A rheological phase diagram of additives for cement formulations. Rheol Acta. doi:10.1007/s00397-013-0685-7

Shindel MM, Swan JW, Furst EM (2013) Calibration of an optical tweezer microrheometer by sequential impulse response. Rheol Acta. doi:10.1007/s00397-013-0698-2

Stadler FJ, Friedrich T, Kraus K, Tieke B, Bailly C (2013) Elongational rheology of NIPAM-based hydrogels. Rheol Acta. doi:10.1007/s00397-013-0690-x

van Deen MS, Bertrand T, Vu N, Quéré D, Clément E, Lindner A (2013) Particles accelerate the detachment of viscous liquids. Rheol Acta. doi:10.1007/s00397-013-0691-9 